\title{
RETRACTED ARTICLE: Serum level estimation of some biomarkers in diabetic and non-diabetic COVID-19 infected patients
}

\author{
Muhammad Usman Faryad Khan ${ }^{1} \cdot$ Baida Rihan $\mathrm{Ali}^{2} \cdot$ Husham Qassim Mohammed ${ }^{3}$. \\ Hayder Mohammed Thyab Al-Shammari ${ }^{4}$. Abduladheem Turki Jalii ${ }^{5,12}$ - Nada Khazal Kadhim Hindi ${ }^{6}$.

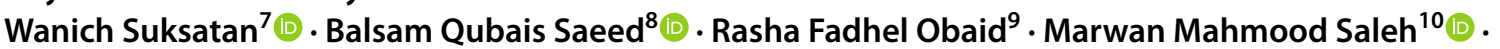 \\ Mustafa M. Kadhim ${ }^{11}$
}

Received: 15 August 2021 / Accepted: 9 October 2021 / Published online: 3 February 2022

(c) King Abdulaziz City for Science and Technology 2021

The Editor-in-Chief and the publisher have retracted this article. The article was submitted to be part of a guest-edited issue. An investigation by the publisher found a number of articles, including this one, with a number of concerns, including but not limited to compromised editorial handling and peer review process, inappropriate or irrelevant references or not being in scope of the journal or guest-edited issue. Based on the investigation's findings the Editor-inChief therefore no longer has confidence in the results and conclusions of this article.

The authors Muhammad Usman Faryad Khan and Abduladheem Turki Jalil disagree with this retraction.

The authors Baida Rihan Ali, Husham Qassim Mohammed, Hayder Mohammed Thyab Al-Shammari, Nada Khazal Kadhim Hindi, Wanich Suksatan, Balsam Qubais Saeed,

Abduladheem Turki Jali

abedalazeem799@gmail.com

Muhammad Usman Faryad Khan

usmanfaryad241@gmail.com

Nada Khazal Kadhim Hindi

nadakhazal@yahoo.com

Wanich Suksatan

wanich.suk@pccms.ac.th

Balsam Qubais Saeed

bsaeed@sharjah.ac.ae

Rasha Fadhel Obaid

Rasha20_12@yahoo.com

Marwan Mahmood Saleh

ah.marwan_bio@uoanbar.edu.iq

1 State Key Laboratory of Silkworm Genome Biology, Southwest University, Chongqing 400716, China

2 Department of Pathological Analysis, College of Science, University of Thi_Qar, Nasiriyah, Iraq

3 Faculty of Nursing, University of Kufa, Kufa, Iraq
Rasha Fadhel Obaid, Marwan Mahmood Saleh and Mustafa M. Kadhim have not responded to correspondence regarding this retraction. The online version of this article contains the full text of the retracted article as Supplementary Information.

Supplementary Information The online version contains supplementary material available at https://doi.org/10.1007/s13204-021-02167-x.

Publisher's Note Springer Nature remains neutral with regard to jurisdictional claims in published maps and institutional affiliations.

Springer Nature or its licensor (e.g. a society or other partner) holds exclusive rights to this article under a publishing agreement with the author(s) or other rightsholder(s); author self-archiving of the accepted manuscript version of this article is solely governed by the terms of such publishing agreement and applicable law.

4 Department of Therapeutic and Drugs, Medicine College, Kufa University, Kufa, Iraq

5 Faculty of Biology and Ecology, Yanka Kupala State University of Grodno, 230023 Grodno, Belarus

6 Department of Basic and Medical Science, College of Nursing, Babylon University, Hillah, Babylon, Iraq

7 Faculty of Nursing, HRH Princess Chulabhorn College of Medical Science, Chulabhorn Royal Academy, Bangkok, Thailand

8 Clinical Sciences Department, College of Medicine, University of Sharjah, Sharjah, UAE

9 Department of Anesthesia Techniques, Al-Mustaqbal University College, Hillah, Babylon, Iraq

10 Department of Biophysics, College of Applied Sciences, University of Anbar, Ramadi, Iraq

11 Department of Dentistry, Kut University College, Kut, Wasit 52001, Iraq

12 College of Technical Engineering, The Islamic University, Najaf, Iraq 